\title{
REVIEW
}

\section{Angiogenesis: a curse or cure?}

\author{
K Gupta, J Zhang
}

Postgrad Med J 2005;81:236-242. doi: 10.1136/pgmi.2004.023309

Angiogenesis, the growth of new blood vessels is essential during fetal development, female reproductive cycle, and tissue repair. In contrast, uncontrolled angiogenesis promotes the neoplastic disease and retinopathies, while inadequate angiogenesis can lead to coronary artery disease. A balance between pro-angiogenic and antiangiogenic growth factors and cytokines tightly controls angiogenesis. Considerable progress has been made in identifying these molecular components to develop angiogenesis based treatments. One of the most specific and critical regulators of angiogenesis is vascular endothelial growth factor (VEGF), which regulates endothelial proliferation, permeability, and survival. Several VEGF based treatments including anti-VEGF and anti-VEGF receptor antibodies/agents are in clinical trials along with several other antiangiogenic treatments. While bevacizumab (anti-VEGF antibody) has been approved for clinical use in colorectal cancer, the side effects of antiangiogenic treatment still remain a challenge. The pros and cons of angiogenesis based treatment are discussed.

See end of article for authors' affiliations

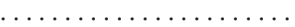

Correspondence to: Dr K Gupta, Division of Hematology, Oncology and Transplantation, University of Minnesota Medical School, Mayo Mail Code 480, 420 Delaware Street SE, Minneapolis, Minnesota 55455, USA; gupta014@ umn.edu

Submitted 21 April 2004 Accepted 25 August 2004
A ngiogenesis fascinated the minds of many for centuries. Leonardo da Vinci speculated that the vasculature developed from the heart, like a tree from the seed and compared the sprouting roots with the capillary meshwork and the tree trunk with the aorta and arteries. ${ }^{1}$ However, the term angiogenesis was coined by John Hunter in 1787, to describe the growth of new blood vessels (http://www.angio.org). Despite its discovery centuries ago, angiogenesis research remained underexplored. In 1971 Judah Folkman proposed the hypothesis that tumour growth is angiogenesis dependent. ${ }^{2}$ Since then publications on angiogenesis have been spiralling in a logarithmic fashion.

\section{ANGIOGENESIS}

Development of blood vessels from in situ differentiating endothelial cells (EC) is called vasculogenesis, whereas sprouting of new blood vessels from the pre-existing ones is termed angiogenesis or neovascularisation. All blood vessels are lined with endothelial cells that must proliferate to form new vessels, migrate to reach remote targets, and survive to limit attrition and senescence. On the other hand the host microenvironment must convey signals for cells to multiply and avoid apoptosis. Disruption of endothelial growth constraints, acquisition of a motile phenotype, dynamic modification of the coupling between cells and the extracellular matrix (ECM), tube formation, and resistance to programmed cell death define the complex, multi-step process of angiogenesis. Successful execution of this process depends upon the delicate balance of growth promoting factors and growth inhibitory factors surrounding the endothelium (table 1).

\section{ANGIOGENESIS PROMOTING GROWTH FACTORS}

Although a vast variety of growth factors and cytokines act as inducers of angiogenesis, vascular endothelial growth factor (VEGF) is the most specific growth factor for vascular endothelium.

\section{Vascular endothelial growth factor/ vascular permeability factor (VEGF/VPF)}

The key feature of the VEGF family of growth factors is their specificity for endothelial cells. VEGF is not a single protein, but a small menagerie of several peptide growth factors of different amino acids in length and type. It was first discovered in 1983 as vascular permeability factor. $^{3}$ In 1989 it was characterised and sequenced by different groups of investigators as an endothelial cell mitogen and called vascular endothelial growth factor. ${ }^{4}$ It differs from the earlier described endothelial mitogen fibroblast growth factor (FGF). VEGF is a secretory protein with a signal peptide, whereas, genes for FGF do not encode for conventional secretory signal peptide and therefore it is believed that FGF remains sequestered in the cells. Because of its diffusibility, VEGF seemed to be a more dynamic regulator of angiogenesis. Since then, several isoforms generated by alternative splicing of a single gene consisting of eight exons and homologs of VEGF have been discovered and ascribed distinct receptors and vascular functions (table 2).

VEGF is required for normal embryonic vasculogenesis and angiogenesis was shown by two separate landmark studies. ${ }^{5} 6$ They found that inactivation of a single allele of VEGF in mice resulted in embryonic lethality. The VEGF $+/-$ embryos experienced growth retardation and other developmental abnormalities that could not be compensated by other VEGF family

Abbreviations: EC, endothelial cell; ECM, extracellular matrix; VEGF, vascular endothelial growth factor; VPF, vascular permeability factor; FGF, fibroblast growth factor; PLGF, placenta derived growth factor; TSP, thrombospondin; PEDF, pigment epithelium derived growth factor; MMP, matrix metalloproteinases; COX-2, cycloxygenase-2; AMD, age related macular degeneration; PTK, protein tyrosine kinase; HIF, hypoxia inducible transcription factor 
members. This led to a turning point in angiogenesis research. Thus VEGF and their receptors have been the most "wanted" target for angiogenic/anti-angiogenic therapy in angiogenesis dependent pathological conditions.

VEGF receptors are type III receptor tyrosine kinases, VEGFRl (Flt-1; fms-like tyrosine kinase) and VEGFR2 (Flk-1/KDR; kinase insert domain containing receptor), are expressed primarily on endothelial cells. ${ }^{7}$ Gene targeting studies show that both VEGFRI and VEGFR2 are essential for development of the embryonic vasculature in mice. Subsequently two other VEGF receptors VEGFR3 (Flt-4), mainly expressed on lymphatic vessels and neuropilin, also expressed on neuronal cells, were also identified (table 2 ). Flk- 1 is considered the most potent mitogenic receptor and neuropilin aids in the binding of VEGF to Flk-1, thus increasing its mitogenic capability. VEGFR3 binds to VEGF-C and VEGF-D to control the growth and maintenance of lymphatic vessels. ${ }^{8}$ VEGFRl is critical in the recruitment of haematopoietic precursors and monocytes to the pathological pro-inflammatory sites and promoting angiogenesis. ${ }^{9}$

\section{Placenta derived growth factor (PLGF)}

PLGF encodes three isoforms: PLGF-1, PLGF-2, PLGF-3. PLGF can bind both VEGFR-1 and VEGFR-2. Flt l and PLGF have a potent and persistent effect on vessel formation. ${ }^{10}$ PLGF stimulates the formation of vessels in ischaemic heart disease, and anti-Fltl, by blocking PLGF effect, can inhibit the neovascularisation in the ischaemic retina and tumours. ${ }^{11}$

Table 1 Positive and negative regulation of angiogenesis

\begin{tabular}{ll}
\hline Activators & Inhibitors \\
\hline Angiogenin & Angiostatin (plasminogen fragment) \\
Angiopoietin-1 & Anti-angiogenic anti-thrombin III \\
AC133 & Canstatin \\
Chemokines* & Cartilage derived inhibitor (CDI) \\
Del-1 & CD59 complement fragment \\
$\beta$-estradiol & Endostatin (collagen XIII fragment) \\
Ephrins & Fibronectin fragment \\
FGF- $\alpha \beta$ & Fragment of SPARC \\
FGF & Heparinases \\
Follistatin & HCG \\
HGF & IFN- $\alpha \beta \gamma$ \\
Id1/Id3 $3 \gamma$ & Interferon inducible protein (IP-10) \\
Integrins, $\alpha$ V $\beta 3, \alpha V \beta 5, \alpha 5 \beta 1$ & IL4, IL12, IL18 \\
IL8 & 2-methoxyestradiol \\
Leptin & Maspin \\
MCP-1 & Kringle-5 (plasminogen fragment) \\
MMPs & Osteopontin fragment \\
NOS & Placental ribonuclease inhibitor \\
PLGF & Plasminogen activator inhibitor \\
PDGF-BB & PEDF (pigment epithelium derived \\
Pleiotrophin (PTN) & growth factor) \\
Platelet derived endothelial cell & PF4 \\
growth factor (PD-ECGF) & \\
P1GF & \\
Proliferin & Prolactin 16 kDa fragment \\
TGF- $\alpha \beta^{*}$ & Retinoids \\
TNF- $\alpha$ & Tissue inhibitor of metalloproteinases \\
VE cadherin & (TIMPs) \\
VEGF & TSP-1 \\
\hline & Vasculostatin \\
\hline
\end{tabular}

Naturally occurring promoters and inhibitors of angiogenesis. *Can have opposite effects. AC133, marker of haematopoietic stem cells, Del-1, developmentally regulated endothelial locus 1 ; FGF, fibroblast growth factor; HGF, hepatocyte growth factor; IL8, interleukin 8; MCP-1, macrophage chemoattractant protein; MMPs, matrix metalloproteases; NOS, nitric oxide synthase; PLGF, placental growth factor; PDGF-BB, platelet derived growth factor-BB; $\mathrm{HCG}$, human chorionic gonadotrophin; IFN, interferon; TGF, transforming growth factor; TNF, tumour necrosis factor; VE cadherin, vascular endothelial cadherin: VEGF, vascular endothelial growth factor; PF4, platelet factor 4; TSP-1, thrombospondin-1.
PlGF and Flt l also play a critical part in the recruitment and homing of circulating endothelial progenitor cells (CEPs) and support monocyte recruitment for vasculogenesis at the site of ischaemia and in tumours.

\section{ANGIOGENESIS INHIBITORS}

Table 1 describes several inhibitors of angiogenesis. The first and the most recently discovered naturally occurring antiangiogenesis inhibitory proteins are described.

Thrombospondin (TSP), a $450 \mathrm{kDa}$ matricellular protein was the first antiangiogenic factor discovered in 1990s. We found that TSP prevented VEGF induced angiogenesis by directly binding to it and by interfering with its binding to cell surface heparan sulphates. ${ }^{12}$ Because of the large size (450 kDa), poor bioavailability, and proteolytic breakdown, clinical use of TSP is limited. However, ABT-510, a mimetic peptide sequence of TSP possessing antiangiogenic activity is in phase II clinical trials.

Pigment epithelium derived growth factor (PEDF) is a secreted glycoprotein with molecular weight of $50 \mathrm{kDa}$. It is a member of the serpin superfamily of serine protease inhibitors and is the most recently discovered antiangiogenesis factor. ${ }^{13}$ PEDF can promote neuronal cell survival but acts as a potent inhibitor of angiogenesis. ${ }^{14}$ Wang et al reported that adenovirus mediated gene transfer of PEDF could significantly reduce tumour neoangiogenesis and tumour growth in animal models with hepatocellular carcinoma and lewis lung carcinoma. ${ }^{15}$

\section{ANGIOGENESIS IN PHYSIOLOGICAL AND PATHOLOGICAL CONDITIONS}

While unregulated angiogenesis is seen in several pathological conditions including psoriasis, nephropathy, cancer, and retinopathy, it is essential for embryonic development, menstrual cycle, and wound repair. The dysregulated and excessive vessel growth can have a significant impact on health, and contribute to various diseases, such as rheumatoid arthritis, obesity, infectious diseases, etc. However, it can also be therapeutic in the treatment of some diseases. Some of the important pathological conditions where it acts as a cause or cure are discussed.

\section{Tumour growth and metastasis}

Progression of tumour growth and metastasis are angiogenesis dependent. After the initial neoplastic transformation, the tumour cells undergo further genetic changes resulting in selection of dominant clones with distinct growth advantage and metastatic potential. ${ }^{16}$ There is an active interaction between the tumour and the blood vessels. Classic studies by Folkman et al in the 1970s showed that tumours cannot grow beyond $1 \mathrm{~mm}$ or $2 \mathrm{~mm}$ without the new blood vessels. ${ }^{2}$ This process is now referred to as an angiogenic switch. It is indeed tilting the balance towards pro-angiogenic tumour microenvironment comprised of hypoxia, increased growth promoting factors/cytokines, decreased antiangiogenic factors, secretion of matrix metalloproteinases (MMPs), and increased cycloxygenase-2 (COX2). ${ }^{17-20}$ More recently proposed mechanisms suggest that in addition to pre-existing endothelial cells, marrow derived endothelial and haematopoietic precursor cells can be mobilised and incorporated into the newly formed tumour vessels. ${ }^{2122}$

\section{Ocular angiogenesis}

Angiogenesis plays a central part in the visual impairment attributable to retinopathy in diabetes, sickle cell disease, retinopathy of prematurity, retinal vascular occlusion, and in age related macular degeneration (AMD). In diabetes hyperglycaemia results in retinal microvascular occlusion 
Table 2 VEGF family of proteins, receptors, and their function

\begin{tabular}{|c|c|c|}
\hline VEGF isoforms/homologues & Receptor(s) & Functionality \\
\hline VEGF 121 & Flt-1, Flk-1/KDR & $\begin{array}{l}\text { Angiogenesis, lower bioactivity as compared } \\
\text { with others }\end{array}$ \\
\hline VEGF 165 & Flt-1, Flk-1/KDR NRP1, NRP2 & $\begin{array}{l}\text { Angiogenesis, optimal characteristics of } \\
\text { bioavailability and biological potency }\end{array}$ \\
\hline VEGF 189 & Flt-1, Flk-1/KDF & Angiogenesis \\
\hline VEGF 206 & Flt-1, Flk-1/KDR & Angic \\
\hline VEGF-B & Flt-1 & Main role is in the cardiovascular system \\
\hline VEGF-C & Flk-1, Flt-4, NRP2 & Lymphangiogenesis, metastatic spread \\
\hline VEGF & Flk-1, Flt-4 & $\begin{array}{l}\text { Angiogenesis, lymphangiogenesis, metastatic } \\
\text { spread }\end{array}$ \\
\hline VEGF-E (viral homologue) & Flk-1, Flt-4 & Mitogen, permeability \\
\hline PLGF & $\begin{array}{l}\text { Flt-1, Flk-, NRP1 (activates VEGFR2 } \\
\text { by transactivation) }\end{array}$ & $\begin{array}{l}\text { Reconstitution of haematopoiesis, } \\
\text { angiogenesis, permeability }\end{array}$ \\
\hline
\end{tabular}

The understanding of VEGF family members and their interactions with specific receptors has been used to develop angiogenesis based treatments. PLGF, not from family of proteins but interacts with VEGF receptors. NRP, neurophilin that is also present on neuronal cells. Flk-1/KDR (kinase insert domain containing receptor); Flt (fmslike tyrosine kinase).

and ischaemia, which can promote angiogenesis because of subsequent hypoxia induced increase in angiogenic growth factors. ${ }^{24}$ Pathogenesis of AMD is not well understood but involves abnormalities of the extracellular matrix in Bruch's basement membrane. Choroidal neovascularisation in this context may be the result of hypoxia of overlying retinal pigment epithelial cells, attributable either to the thickening of Bruch's membrane or to abnormalities of choroidal perfusion, leading to the expression of pro-angiogenic cytokines. ${ }^{24}$ Laser pan-retinal photocoagulation is presently the conventional treatment for these conditions. ${ }^{25}$ However, it may not be effective in all cases and may have side effects. Newer treatments including recombinant adeno associated virus mediated local gene transfer of VEGF inhibitors, inhibitors of intracellular signalling cascades, and use of endogenous inhibitors such as pigment epithelium derived growth factor (PEDF) seem to be more promising. ${ }^{26}$

\section{THERAPEUTIC ANGIOGENESIS}

\section{In tissue remodelling}

Recently stem cell derived vascular cells or endothelial progenitor cells (EPCs) have attracted significant attention because of their capability for (re)vascularisation called vasculogenesis. ${ }^{27} 28$ Vasculogenesis resembles the embryological process where the haematopoietic/endothelial progenitors, "haemangioblasts" differentiate into blood cells as well as blood vessels. These endothelial precursors in an adult are derived primarily from bone marrow but increasing evidence is accumulating regarding their tissue specific origins. These precursors, whether embryonic or adult, may have no or little contribution physiologically in an adult, but seem promising in organ repair and tissue remodelling and promoting tumour growth. ${ }^{21} 29$ It has been shown that liver organogenesis is promoted by endothelial cells before vascular function. ${ }^{30}$

\section{In cardiovascular disease}

Angiogenesis is even more critical in cardiovascular disease. Various angiogenic agents are in clinical trials for treating ischaemic heart disease. However, one growth factor may not be sufficient by itself, but may require additional growth promoting cytokines. VEGF and PlGF have been shown to stimulate angiogenesis and collateral growth with comparable efficiency in the ischaemic heart and limb. ${ }^{11}$ This and other studies show that additional mechanisms including the recruitment of myeloid progenitors and haematopoietic precursors are also required in addition to angiogenic agents to stimulate the growth of new vessels in the ischaemic tissue. ${ }^{31}$ The formation of new vessels by tissue engineering holds promise to regenerate vessels for cardiac collateralisation and in vascular healing. ${ }^{32}$

\section{In wound healing}

The formation of new blood vessels provides a route for oxygen and nutrient delivery, as well as a conduit for components of the inflammatory response during the healing of wounds. Pro-angiogenic treatments have shown remarkable promise in the healing of wounds in pathological conditions. Kirchner et al reported that topical use of VEGF had $50 \%$ improvement in time for wound healing in diabetic mice. ${ }^{33}$ Galeano et al also suggested VEGF gene transfer might be a new approach to treat wound healing disorders associated with diabetes. ${ }^{34}$ It is encouraging that recombinant platelet derived growth factor-BB (rhPDGF-BB) has been approved to treat diabetic neuropathic foot ulcers. ${ }^{35}$ Table 3 shows angiogenesis based experimental/clinical trial treatment for wound healing.

\section{THERAPEUTIC AGENTS IN ANGIOGENESIS DEPENDENT PATHOLOGICAL DISEASES}

Since the 1990s there has been a voluminous rise in antiangiogenic treatments and several angiogenesis inhibitors are in pre-clinical/clinical trials (table 4). (http:// www.cancertrials.nci.nih.gov). Based on their mechanism of action, angiogenesis based treatment is classified into:

\section{Exogenous or endogenous inhibitors of angiogenic growth factors or their receptors}

These include proteins, cytokines, and antibodies that directly bind to the growth factor or its receptor. One of the endogenous proteins discussed in this review is TSP. Others are described in table 1 . These proteins by themselves may be too large and subject to proteolysis. Therefore, peptide sequences with antiangiogenic activity derived from these proteins are being developed, for example, ABT-510, a peptide sequence from type 1 repeats domain of TSP. Several antibodies of growth factors and their receptors, including a wide array of VEGF and VEGF receptor antibodies, are showing promise in pre-clinical studies and clinical trials (table 4). Bevacizumab, an antibody to VEGF, has been approved for clinical use and is discussed later in this review.

\section{Inhibitors of endothelial cell growth and survival}

Angiogenesis depends upon endothelial proliferation and survival. Cancer as a disease is characterised by deregulated proliferation and survival due to dysregulated upregulation of cell cycle protein cyclin D and survival signal Akt. ${ }^{36}$ Inhibitors of cell proliferation and/or survival include agents that act 
Table 3 Angiogenesis based treatments in experimental and clinical trial therapy for wound healing

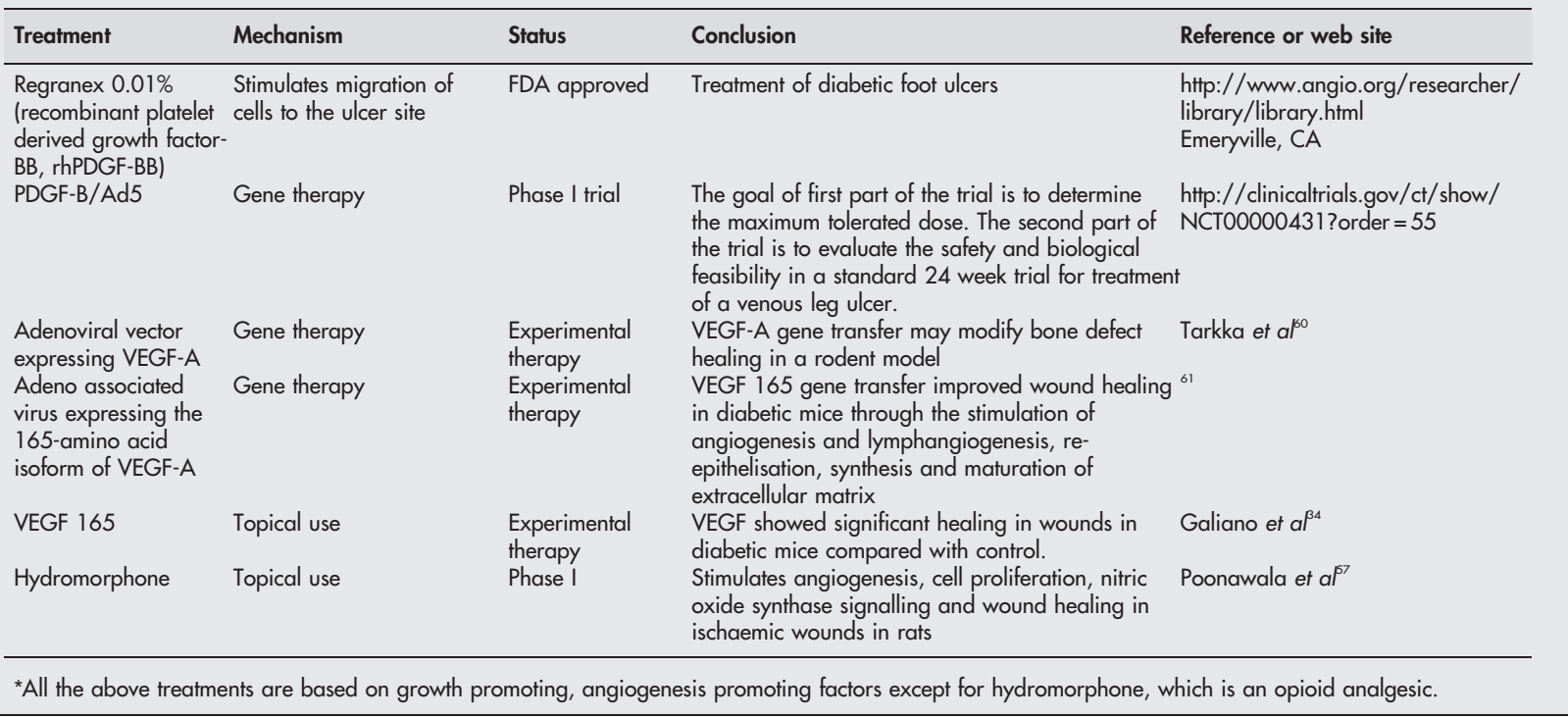

directly on these processes in endothelium or indirectly by stimulating the activation or release of another protein. Some of the antiangiogenic agents that act directly are angiostatin, arresten, endostatin, 2-methyoxyestradiol, etc (table 3). Indirect antiangiogenic agents, such as herceptin, inhibit the secretion of pro-angiogenic factors VEGF, angiopoietin-1, and TGF- $\beta$ and upregulate the inhibitory protein TSP-1, which lead to the inhibition of endothelial proliferation and survival.

\section{Inhibitors targeting the basement membrane and extracellular matrix}

One of the cardinal features for endothelial proliferation, migration, and survival is the EC-matrix interaction. Cell surface integrins $\alpha_{V} \beta_{3}$ and other integrins mediate this interaction. Blockers of these integrins and cell-matrix interaction can potentially block angiogenesis. Some of the blockers in clinical trials are constatin, tumstatin, and vitaxin..$^{37-40}$ Some of these are currently under clinical trials and their outcome remains to be known.

\section{Inhibitors of angiogenic signalling pathway}

Oncogenic participants in the angiogenic signalling pathways include protein tyrosine kinase (PTK), MAPK/ERK, Akt, Bcl2 , p53, and cell cycle proteins that promote cell proliferation and survival. These are reasonably specific targets to inhibit angiogenesis and have led to the development of small molecular size PTK inhibitors for the treatment of cancer. ${ }^{41}$ The PTK inhibitor, Gleevec (imatinib mesylate) specifically targets the BCR-Abl and c-kit tyrosine kinases. ${ }^{42}$ PTK inhibitors bind to the ATP binding site of the receptor, and thus prevent its subsequent phosphorylating capability. These are low molecular weight compounds and thus nonimmunogenic. ${ }^{41}$ Other PTK inhibitors that specifically interfere with angiogenesis are VEGF R2 selective, SU5416, ${ }^{43}$ PTK $787,{ }^{44}$ and ZD6474. ${ }^{45}$ Therefore, these agents have been more successful than others as antiangiogenic agents.

\section{RATIONALE FOR ANGIOGENESIS BASED TREATMENTS IN CANCER}

Most of the development in antiangiogenic treatment is targeted towards cancer because of tremendous heterogeneity of different cancers and only one common feature of increased angiogenesis among different cancers. Some of the major advantages of angiogenesis based treatment over others are:

(1) A single vessel provides the nutrition for thousands of tumour cells and has to be damaged at only one point to block blood flow upstream and downstream.

(2) A change of shape of local initiation of blood coagulation may be sufficient, other than killing the endothelial cells

(3) The endothelial cell is a normal diploid cell, which is unlikely to acquire genetic mutations that render it drug resistant.

(4) Blood flow, a surrogate marker for biological activity, is measurable in the clinic.

(5) Temporary effects on vascular function may be sufficient to kill the endothelial cells. ${ }^{46}$

\section{LIMITATIONS OF ANGIOGENESIS BASED TREATMENTS}

Most of the angiogenesis based treatments have worked in experimental rodent models but have not been successful in clinical trials. First of all, antiangiogenesis treatments target actively proliferating endothelial cells. However, the relative number of proliferating EC is far smaller in human tumours than in rodent tumour models. ${ }^{47}$ Mature vessels in human tumour at any given time may not undergo regression with the conventional antiangiogenic agents. Thus, additional markers associated specifically with specific pathological angiogenesis need to be identified. Secondly, multiple growth factors, receptors, and other components of the microenvironment support angiogenesis. Therefore, treatment targeted to a single factor may not be completely effective. Thirdly, vasculature is tissue and/or tumour type specific. Moreover, vascular mimicry-where the tumour vasculature presents genomic and phenotypic similarities with that of the tumour cells $^{48}$ - makes the tumour microvasculature more unpredictable than it is perceived to be. Fourthly, the drug delivery to the ischaemic site can be a major limiting factor, specifically without any tools to monitor the site specific drug availability within the tumour. Moreover, it is not yet feasible to monitor the antiangiogenic response in the patients. However, with the recent advances in magnetic resonance imaging it may be possible to do vascular imaging in patients.

In addition, angiogenesis based treatment is more effective in small tumours than advanced cancers; however, most of the 
Table 4 Angiogenesis inhibitors in pre-clinical/clinical trials

\begin{tabular}{|c|c|c|c|}
\hline Drug name & Mechanism & Pre-clinical/clinical trial & Company and reference \\
\hline PTK787/ZK225 & Block VEGF & $\begin{array}{l}\text { Phase I against advanced cancers, glioblastoma and Kaposi's sarcoma, and } \\
\text { phase I/II against Von Hippel Lindau disease }\end{array}$ & Novartis, East Hanover, NJ \\
\hline Rhu Mab VEGF & $\begin{array}{l}\text { Monoclonal antibody } \\
\text { against VEGF }\end{array}$ & $\begin{array}{l}\text { Phase II metastatic renal cell cancer, phase II with chemotherapy in untreated } \\
\text { advanced colorectal, metastatic breast; phase II non-Hodgkin's lymphoma, } \\
\text { haematological malignancies, metastatic prostate, previously untreated advanced } \\
\text { colorectal, inflammatory breast cancer, advanced or recurrent cervical, non-small } \\
\text { cell lung; phase II/III advanced non-small cell lung; phase III with chemotherapy in } \\
\text { untreated metastatic colorectal, phase III metastatic breast. }\end{array}$ & 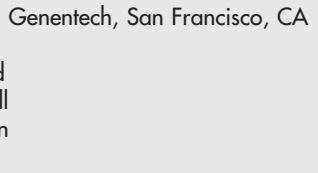 \\
\hline SU6668 & $\begin{array}{l}\text { Blocks VEGF-R2, FGF-R } \\
\text { PDGF-R }\end{array}$ & Currently in phase II clinical trial. & Sugen, S. San Francisco, CA \\
\hline SU11248 & $\begin{array}{l}\text { Multi-targeted kinase } \\
\text { inhibitor }\end{array}$ & $\begin{array}{l}\text { Results of preclinical indicate encouraging activity. Phase I clinical trials are } \\
\text { being conducted to help define the safety, tolerability, and optimal dose and } \\
\text { regimen of SU1 } 1248 \text { in the treatment of different cancers. }\end{array}$ & $\begin{array}{l}\text { http://www.sugen. com/ } \\
\text { webpage_templates/ } \\
\text { home.php3 }\end{array}$ \\
\hline IMC-1121b & Targets VEGF-R2 & Phase I clinical trial & ImClone, Branchburg, NJ \\
\hline Cp-547,632 & Block VEGF signalling & Phase $I$ in advanced solid tumours. & $\begin{array}{l}\text { OSI Pharmaceuticals, Melville, } \\
\text { NY }\end{array}$ \\
\hline Angiozyme & Targets VEGF-R2 and -R1 & Phase II breast and colorectal cancer & $\begin{array}{l}\text { Ribozyme Pharmaceuticals, } \\
\text { Boulder, CO }\end{array}$ \\
\hline Endostatin & $\begin{array}{l}\text { EC proliferation and } \\
\text { migration }\end{array}$ & Phase II neuroendocrine tumours and metastatic melanoma & $\begin{array}{l}\text { EntreMed, Rockville, MD http:// } \\
\text { entremed.com }\end{array}$ \\
\hline Angiostatin & $\begin{array}{l}\text { ATP synthase, inhibits EC } \\
\text { proliferation }\end{array}$ & $\begin{array}{l}\text { Two phase I trials being conducted, including angiostatin in combination with } \\
\text { radiation therapy. }\end{array}$ & $\begin{array}{l}\text { EntreMed, Rockville, MD http:// } \\
\text { entremed.com }\end{array}$ \\
\hline Panzem & $\begin{array}{l}\text { Targets both tumour cells } \\
\text { and their blood vessels }\end{array}$ & $\begin{array}{l}\text { Ongoing: phase I clinical trials for advanced solid tumours and phase II for } \\
\text { multiple myeloma. Completed: phase II - prostate }\end{array}$ & $\begin{array}{l}\text { EntreMed, Rockville, MD http:// } \\
\text { entremed.com }\end{array}$ \\
\hline BMS-275291 & Synthetic MMP inhibitor & $\begin{array}{l}\text { Phase I/II Kaposi's sarcoma; phase II/III advanced or metastatic non-small cell } \\
\text { lung cancer }\end{array}$ & $\begin{array}{l}\text { Bristol-Myers Squibb New York, } \\
\text { NY }\end{array}$ \\
\hline Thalidomide & $\begin{array}{l}\text { Decrease TNF } \alpha \text {, bFGF, } \\
\text { VEGF }\end{array}$ & $\begin{array}{l}\text { Phase I malignant glioma, phase I/II for advanced melanoma, phase II ovarian, } \\
\text { metastatic prostate, phase II with chemotherapy against solid tumours, adjuvant } \\
\text { study in recurrent or metastatic colorectal cancer; myelofibrosis with myeloid } \\
\text { metaplasia, follicular lymphoma myelodysplastic syndrome, refractory ovarian, } \\
\text { phase II gynaecological sarcomas, liver cancer; metastatic melanoma, CLL, multiple } \\
\text { myeloma; phase III non-small cell lung, non-metastatic prostate, refractory multiple } \\
\text { myeloma, renal cancer. }\end{array}$ & $\begin{array}{l}\text { Celgene Warren, NJ } \\
\text { e }\end{array}$ \\
\hline ENMD 0996 & Targets FGF-2 & Preclinical & $\begin{array}{l}\text { EntreMed, Rockville, MD http:// } \\
\text { entremed.com }\end{array}$ \\
\hline CAl & Inhibitor of calcium influx & $\begin{array}{l}\text { Phase I studies in combination against solid tumours, phase II ovarian cancer, } \\
\text { metastatic renal cell cancer. }\end{array}$ & $\begin{array}{l}\text { National Cancer Institute, } \\
\text { Bethesda, MD }\end{array}$ \\
\hline Celecoxib & COX-2 inhibitor & $\begin{array}{l}\text { Phase I prostate cancer; phase I/II cervical cancer; phase II basal cell cancer, } \\
\text { metastatic breast cancer. }\end{array}$ & Pharmacia Peapack, NJ \\
\hline
\end{tabular}

prevailing clinical trials are carried out in the setting of advanced disease. Moreover, there is still concern about the effect on physiological forms of angiogenesis in various situations. Thus, wound healing would be adversely affected in a cancer patient receiving antiangiogenic drugs, as reproductive angiogenesis would be. Antiangiogenic treatment is most effective in small primary tumour and metastasis with a good blood supply. Different kinds of cancers should follow individual strategy for angiogenesis based treatment. For instance, breast cancer can release more, and different types of pro-angiogenic proteins with passage of time, while high grade giant cell tumours and angioblastomas produce only or mainly $\beta$-FGF. Also, endothelium is genetically stable, so the treatment can be repeated. Duration of treatment is presently unclear, but many propose long term maintenance. Several modes of drug delivery including metronomic delivery at spaced intervals alternating with chemotherapeutic combinations are in progress. ${ }^{49}$ Most of these treatments hold promise but will have to be clinically tested for different kinds and different stages of tumour growth. Despite these limitations, several angiogenesis based treatments hold promise in clinical trials and two have been approved for clinical use (table 4), which are described below.

\section{FOOD AND DRUG ADMINISTRATION (FDA) APPROVED ANGIOGENESIS BASED TREATMENTS Avastin}

Bevacizumab (commercially called Avastin) is the first approved anticancer agent developed on angiogenesis based treatment. Bevacizumab is a recombinant humanised monoclonal antibody directed against VEGF. It has shown significant activity in the treatment of a number of solid tumours in clinical trials. It was significantly effective when used in combination with fluorouracil based chemotherapy and led to improvement in overall response rates, time to progression, and survival in patients with metastatic colon cancer..$^{50}$ Bevacizumab and IFL (irinotecan, fluorouracil, leucovorin) chemotherapy regimen showed an increase in median survival by 4.7 months, in progression free survival by 4.36 months and in overall response rates (complete and partial responses) by $10.2 \%$, as compared with IFL plus placebo. ${ }^{50}$ Most frequent adverse effects associated with bevacizumab in both phase II and III clinical trials were hypertension, bleeding episodes, and thrombotic events and proteinuria. ${ }^{50}$ Therefore, use of bevacizumab warrants caution while being used in patients with hypertension, thromboembolism, bleeding, or pre-existing proteinuria.

\section{Regranex}

Regranex $0.01 \%$ (recombinant platelet derived growth factor-BB, rhPDGF-BB, becaplermin, Ortho-McNeil Pharmaceuticals product) is approved by FDA for the treatment of diabetic neuropathic foot ulcers. ${ }^{35}$ Based on the preclinical/clinical outcome of angiogenesis based treatment, we are cautiously optimistic that targeting angiogenesis combined with chemotherapy or radiotherapy will eventually enter the clinics to treat the cancer. 
SUMMARY OF OTHER ANGIOGENESIS BASED CLINICAL TRIALS AND FDA APPROVED DRUGS

Up to the end of February, 2004, there are 171 active antiangiogenesis clinical trials sponsored by the NCI, university/ institutions, and other pharmaceutical companies, among which are 28 phase III or IV clinical trials. Another 178 clinical trials have been closed. Some drugs have been proved to be ineffective and suspended for further clinical trials. For example, SU5416, which showed promise in animal studies as well as early clinical trials, has been shelved because of a lack of efficacy in phase III trials. Marimastat, prinomastat (AG3340), and BAY 12-9566 are three MMP inhibitors that have proved not to be effective in phase III clinical trials.

\section{OTHER PROMISING ANGIOGENESIS BASED TREATMENTS}

\section{Gene therapy}

A variety of viral and non-viral methods are being assessed: retroviruses, adenoviruses, cationic liposomes. ${ }^{51}$ Delivery of these genes and maintenance of long term gene expression at high levels remains challenging in vivo. In terms of the patients with retinal neovascular disease, the high systemic doses required to achieve therapeutic intraocular levels would be expensive and hazardous, because of the blood-retinal barrier. In contrast, gene treatment provides the possibility of localised, targeted, sustained delivery of therapeutic proteins into an appropriate intraocular site. Brainbrid et al showed that inhibition of VEGF by local gene transfer of its soluble receptor sFlt-1 consistently reduces neovascularisation by $50 \%{ }^{24}$ Recently, another group used adenovirus vector containing an angiostatic molecule that targets the uPA/ UPAR system or endostatin reduced retinal neovascularisation by 78.1 and $79.2 \%$, respectively, in a mouse model of hypoxia induced neovasculariaation..$^{52}$

\section{HIFs}

Hypoxia is a strong stimulus for angiogenesis in numerous disorders, and it can switch on the expression of several angiogenic factors including VEGF, nitric oxide synthase, PDGF etc, via activating hypoxia inducible transcription factors (HIFs). HIF- 1 is an $\alpha \beta$-heterodimer that was first recognised as a DNA binding factor. Both HIF- $\alpha$ and $\beta$ subunits exist as a series of isoforms encoded by distinct genetic loci. Among three isoforms of HIF- $\alpha$, HIF- $1 \alpha$ and HIF$2 \alpha$ are more closely related with hypoxia response elements to induce transcriptional activity. ${ }^{53}$ Several strategies have been carried out in the experimental treatment based on HIF$\alpha$. However, the most exciting possibility is the use of small molecule inhibitors of the HIF hydroxylases. For example, favourable response to one such compound, FG004l, in a rat model of myocardial infarction was seen even in the face of little detectable fibrosis in control animals. ${ }^{54}$

\section{Morphine}

Morphine is widely used to treat pain in cancer patients. Although the effects of morphine on central nervous systems have been studied widely, we know little about morphine's activity on non-neuronal systems, including vascular endothelium. It has been shown that endothelial cells express specific opioid receptors, including $\mu$ opioid receptor. Our laboratory showed that morphine at medically relevant concentrations stimulates tumour growth by promoting tumour angiogenesis. ${ }^{55}$ It does so by nitric oxide mediated activation of MAPK/ ERK and by stimulating the survival signal PKB/Akt, inhibition of apoptosis, and promotion of cell cycle progression by increasing cyclin Dl. Tumour promoting effects of morphine have also been shown in mice model of leukaemia or sarcoma. ${ }^{56}$ However, the use of morphine and other opioids in wound healing and cardiovascular disease can have therapeutic implications. We are currently testing the topical use of hydromorphone for wound healing in phase I clinical trials. In pre-clinical studies morphine hydromorphone and fentanyl promoted healing of ischaemic wounds in rats. ${ }^{57}$ We believe that topical use of opioids in wound healing will also provide pain relief without the side effects of systemically administered opioids. Importantly, opioid receptors provide additional promising targets for angiogenesis based treatments.

\section{Combination therapy}

Tumours become self reliant, although still nurtured by the blood vessels, and therefore targeting both the vessel as well as the tumour cells may be a reasonable strategy. Administration of recombinant proteins together with chemotherapy yielded a potent anticancer effect in ovarian and pancreatic cancer models. ${ }^{23}$ Radiation can damage the tumour cells within the centre of the tumour, but can upregulate hypoxia inducible factor, which can increase the expression of VEGF. The combination of antiangiogenic drugs and radiation has been shown to have potent antitumour effects. ${ }^{58}$ During this treatment modality, angiogenesis based drugs may work as radiation sensitisers, facilitating the entrance of radiation into the tumour. Angiostatin in combination with radiation therapy is being evaluated in a phase I clinical trial. ${ }^{23}$ Anti-VEGF treatment can potentiate radiation therapy as well as decrease resistance of tumour cells. ${ }^{59}$

\section{CONCLUSION AND FUTURE RESEARCH DIRECTION}

We are faced with the challenge of angiogenesis based treatments. It is not easy to define the optimal treatment dose and schedule, the optimal combination of antiangiogenic therapy, and other anticancer modalities. Newer angiogenic factors are still being discovered raising the possibility of multiple factors involved in different cancers/pathological conditions. While these newer factors complicate the already complex milieu of angiogenesis, at the same time they provide additional therapeutic targets, taking us a step closer to finding an ultimate solution. With at least two approved angiogenesis based drugs (bevacizumab and PDGF-BB) being used in the clinical setting, we are hopeful that more angiogenesis based treatments will be available to patients in the near future.
ANGIOGENESIS!
When growing,
Will heal the wounds
And bypass clots
The brain the heart
And your bald spots! Cancer
And endometriosis
And stop vessel clogs
In atherosclerosis!
The two faces
Of friend or foe
Can help or destroy
We assume it so.
But the future holds
What we shall see
In Angiogenesis
For you and me.

Endothelial cells proliferating

New blood vessels are creating and making

But it must be stopped to help the retinopathy and Obesity!

\section{ACKNOWLEDGEMENTS}

The authors thank Mihir Gupta for the angiogenesis poetry and Ms Carol Taubert for word processing of the manuscript. 


\section{Authors' affiliations}

K Gupta, Division of Hematology, Oncology and Transplantation, University of Minnesota Medical School, Minneapolis, USA J Zhang, Department of Surgery, Shanghai Cancer Hospital, Fudan University, Shanghai, China and Fred Hutchinson Cancer Research Center, Public Health Science, Seattle, Washington, USA

Funding: this work was supported by a National Institutes of Health grant (HL68802-01) and a Susan G Komen Breast Cancer Foundation grant to KG.

Conflicts of interest: none declared.

\section{REFERENCES}

1 Risau W. Mechanisms of angiogenesis. Nature 1997;386:671-4.

2 Folkman J. Tumor angiogenesis: therapeutic implications. N Engl J Med 1971;285:1182-6.

3 Senger DR, Galli SJ, Dvorak AM, et al. Tumor cells secrete a vascular permeability factor that promotes accumulation of ascites fluid. Science 1983;219:983-5.

4 Gerber HP, Malik AK, Solar GP, et al. VEGF regulates haematopoietic stem cell survival by an internal autocrine loop mechanism. Nature 2002:417:954-8.

5 Carmeliet P, Jain RK. Angiogenesis in cancer and other diseases. Nature 2000;407:249-57.

6 Ferrara N. Role of vascular endothelial growth factor in regulation of physiological angiogenesis. Am J Physiol Cell Physiol 2001;280:C1358-66.

7 Ferrara N. VEGF: an update on biological and therapeutic aspects. Curr Opin Biotechnol 2000;11:617-24.

8 Ferrara N. VEGF and the quest for tumour angiogenesis factors. Nat Rev Cancer 2002;2:795-803.

9 Rafii S, Lyden D, Benezra $R$, et al. Vascular and haematopoietic stem cells: novel targets for anti-angiogenesis therapy? Nat Rev Cancer 2002;2:826-35.

10 Isner JM. Myocardial gene therapy. Nature 2002;415:234-9.

11 Luttun A, Tiwa M, Moons L, et al. Revascularization of ischemic tissues by PIGF treatment, and inhibition of tumor angiogenesis, arthritis and atherosclerosis by anti-Flt1. Nat Med 2002;8:831-40.

12 Gupta K, Gupta P, Wild R, et al. Binding and displacement of vascular endothelial growth factor (VEGF) by thrombospondin: effect on human microvascular endothelial cell proliferation and angiogenesis. Angiogenesis 1999:3:147-58.

13 Becerra S, Sagasti A, Spinella P. Pigment epithelium-derived factor behaves like a noninhibitory serpin: Neurotrophic activity does not require the serpin reactive loop. J Biol Chem 1995;270:25992-9.

14 Doll JA, Stellmach VM, Bouck NP, et al. Pigment epithelium-derived factor regulates the vasculature and mass of the prostate and pancreas. Nat Med 2003;9:774-80.

15 Wang L, Schmitz V, Perez-Mediavilla A, et al. Suppression of angiogenesis and tumor growth by adenoviral-mediated gene transfer of pigment epithelium-derived factor. Mol Ther 2003;8:72-9.

16 Zhang J, Shen KW, Liu G, et al. Antigenic profiles of disseminated breast tumour cells and microenvironment in bone marrow. Eur J Surg Oncol 2003;29:121-6.

17 Tonini T, Rossi F, Claudio PP. Molecular basis of angiogenesis and cancer. Oncogene 2003;22:6549-56.

18 Folkman J. Role of angiogenesis in tumor growth and metastasis. Semin Oncol 2002;29(suppl 16):15-18.

19 Liotta LA, Stetler-Stevenson WG. Tumor invasion and metastasis: an imbalance of positive and negative regulation. Cancer Res 1991;51/suppl 18):5054-9s

20 Chang SH, Liu CH, Conway R, et al. Role of prostaglandin E2-dependent angiogenic switch in cyclooxygenase 2-induced breast cancer progression. Proc Natl Acad Sci USA 2004;101:591-6.

21 Ruzinova MB, Schoer RA, Gerald W, et al. Effect of angiogenesis inhibition by ld loss and the contribution of bone-marrow-derived endothelial cells in spontaneous murine tumors. Cancer Cell 2003;4:277-89.

22 Zhang $F$, Cheng J, Hackett NR, et al. Adenovirus E4 gene promotes selective endothelial cell survival and angiogenesis via activation of the VE-cadherin/ Akt signaling pathway. J Biol Chem 2004;279:11760-6.

23 Scappaticci FA. Mechanisms and future directions for angiogenesis-based cancer therapies. J Clin Oncol 2002;20:3906-27.

24 Bainbridge JW, Mistry AR, Thrasher AJ, et al. Gene therapy for ocular angiogenesis. Clin Sci (Lond) 2003;104:561-75.

25 The Diabetic Retinopathy Study Research Group. Photocoagulation treatment of proliferative diabetic retinopathy. Clinical application of diabetic retinopathy study (DRS) findings, DRS Report Number 8. Ophthalmology 1981;88:583-600.

26 Aiello LP, Cahill MT, Cavallerano JD. Growth factors and protein kinase C inhibitors as novel therapies for the medical management diabetic retinopathy. Eye 2004;18:117-25.

27 Zwaginga JJ, Doevendans. Stem cell-derived angiogenic/vasculogenic cells: possible therapies for tissue repair and tissue engineering. Clin Exp Pharmacol Physiol 2003;30:900-8.

28 Tepper OM, Sealove BA, Murayama T, et al. Newly emerging concepts in blood vessel growth: recent discovery of endothelial progenitor cells and their function in tissue regeneration. J Investig Med 2003;51:353-9.
29 Rafii S, Lyden D. Therapeutic stem and progenitor cell transplantation for organ vascularization and regeneration. Nat Med 2003;9:702-12.

30 Matsumoto K, Yoshitomi H, Rossant J, et al. Liver organogenesis promoted by endothelial cells prior to vascular function. Science $2001 ; 294: 559-63$

31 Avecilla ST, Hattori K, Heissig B et al. Chemokine-mediated interaction of hematopoietic progenitors with the bone marrow vascular niche is required for thrombopoiesis. Nat Med 2004;10:64-71.

32 Koike N, Fukumura D, Gralla O, et al. Tissue engineering: creation of longlasting blood vessels. Nature 2004;428:138-9.

33 Kirchner LM, Meerbaum SO, Gruber BS et al. Effects of vascular endothelial growth factor on wound closure rates in the genetically diabetic mouse model. Wound Repair Regen 2003;11:127-31

34 Galiano RD, Tepper OM, Pelo CR, et al. Topical vascular endothelial growth factor accelerates diabetic wound healing through increased angiogenesis and by mobilizing and recruiting bone marrow-derived cells. Am J Pathol 2004; 164:1935-47.

35 Angiogenesis Research Library. http://www.angio.org/researcher/library/ library.html.

36 Kerbel R, Folkman J. Clinical translation of angiogenesis inhibitors. Cancer Rev 2002;2:727-39.

37 Kamphaus GD, Colorado PC, Panka DJ, et al. Canstatin, a novel matrixderived inhibitor of angiogenesis and tumor growth. J Biol Chem 2000;275:1209-15.

38 Maeshima Y, Manfredi M, Reimer C, et al. Identification of the antiangiogenic site within vascular basement membrane-derived tumstatin. J Biol Chem 2001;276:15240-8

39 Maeshima Y, Sudhakar A, Lively JC, et al. Tumstatin, an endothelial cellspecific inhibitor of protein synthesis. Science 2002;295:140-3.

40 Gutheil JC, Campbell TN, Pierce PR, et al. Targeted antiangiogenic therapy for cancer using vitaxin: a humanized monoclonal antibody to the integrin av33. Clin Cancer Res, 2000;6:3056-61.

41 Fabbro D, Parkinson D, Matter A. Protein tyrosine kinase inhibitors: new treatment modalities? Curr Opin Pharmacol 2002:2:374-81.

42 Savage DG, Antman KG. Imatinib mesylate-a new oral targeted therapy. N Engl J Med 2002;346:683-93

43 Fong TA, Shawver LK, Sun L, et al. SU5416 is a potent and selective inhibitor of the vascular endothelial growth factor receptor (FCR/KDR) that inhibits tyrosine kinase catalysis, tumor vascularization, and growth of multiple tumor types. Cancer Res 1999;59:99-106.

44 Wood JM, Bold G, Buchdunger E, et al. PTK787/ZK 222584, a novel and potent inhibitor of vascular endothelial growth factor receptor tyrosine kinases, impairs vascular endothelial growth factor-induced responses and tumor growth after oral administration. Cancer Res 2000;60:2178-89.

45 Wedge SR, Ogilvie DJ, Dukes M, et al. ZD6474 inhibits vascular endothelial growth factor signaling, angiogenesis, and tumor growth following oral administration. Cancer Res 2002;62:4645-55.

46 Thorpe PE, Chaplin DJ, Blakey DC. The first international conference on vascular targeting: Meeting overview. Cancer Res 2003;63:1144-7.

47 Eberhard A, Haklert S, Groede V, et al. Heterogeneity of angiogenesis and blood vessel maturation in human tumors: Implications for antiangiogenic tumor therapies. Cancer Res 2000;60:1388-93.

48 Fidler IJ, Ellis LM. Neoplastic angiogenesis. N Engl J Med 2004;351:215-16.

49 Bocci G, Francia G, Man S, et al. Thrombospondin 1, a mediator of the antiangiogenic effects of low-dose metronomic chemotherapy. Proc Natl Acad Sci USA 2003;100:12917-22.

50 Zondor SD, Medina PJ. Bevacizumab: An angiogenesis inhibitor with efficacy in colorectal and other malignancies. Ann Pharmacol 2004;38:1258-64.

51 Takeuchi Y, Kurohane K, Ichikawa K, et al. Induction of intensive tumor suppression by antiangiogenic photodynamic therapy using polycationmodified liposomal photosensitizer. Cancer 2003;97:2027-34.

52 Le Gat L, Gogat K, Bouquet $C$, et al. In vivo adenovirus-mediated delivery of a UPA/UPAR antagonist reduces retinal neovascularization in a mouse model of retinopathy. Gene Ther 2003;10:2098-103.

53 Pugh CW, Ratcliffe PJ. Regulation of angiogenesis by hypoxia: role of the HIF system. Nat Med 2003;9:677-84.

54 Nwogu Jl, Geenen D, Bean $M$, et al. Inhibition of collagen synthesis with prolyl 4- hydroxylase inhibitor improves left ventricular function and alters the pattern of left ventricular dilatation after myocardial infarction. Circulation $2001 ; 104: 2216-21$

55 Gupta K, Kshirsagar S, Chang L, et al. Morphine stimulates angiogenesis by activating proangiogenic and survival-promoting signaling and promotes breast tumor growth. Cancer Res 2002;62:4491-8.

56 Ishikawa M, Tanno K, Kamo A, et al. Enhancement of tumor growth by morphine and its possible mechanism in mice. Biol Pharm Bull 1993;16:762-6.

57 Poonawala T, Levay-Young BK, Hebbel RP, et al. Opioids heal ischemic wounds in rats. Wound Repair and Regeneration 2005;13:165-74.

58 Holash J, Maisonpierre PC, Compton D, et al. Vessel cooption, regression, and growth in fumors mediated by angiopoietins and VEGF. Science 1999;284:1994-8.

59 Gorski DH, Beckett MA, Jaskowiak NT, et al. Blockage of the vascular endothelial growth factor stress response increases the anti-tumor effects of ionizing radiation. Cancer Res 1999;59:3374-8.

60 Tarkka T, Sipola A, Jamsa T, et al. Adenoviral VEGF-A gene transfer induces angiogenesis and promotes bone formation in healing osseous tissues. J Gene Med 2003;5:560-6

61 Hong Y-K, Lange-Asschenfeldt B, Velasco P, et al. VEGF-A promotes tissue repair-associated lymphatic vessel formation via VEGFR-2 and the $\alpha 1 \beta 1$ and $\alpha 2 \beta 1$ integrins. FASEB J 2004; Express article 10.1046/fj.03-1179fje. 